\title{
Vascular approaches and its potential implications in transcatheter aortic valve implantation
}

\author{
Alessandro Sticchi, Edoardo Bressi, Annunziata Nusca, Germano Di Sciascio \\ Unit of Cardiovascular Science, Campus Bio-Medico University, Rome 00128, Italy. \\ Correspondence to: Dr. Alessandro Sticchi, Unit of Cardiovascular Science, Campus Bio-Medico University, Rome 00128, Italy. \\ E-mails: sticchialessandro@gmail.com; a.sticchi@unicampus.it
}

How to cite this article: Sticchi A, Bressi E, Nusca A, Di Sciascio G. Vascular approaches and its potential implications in transcatheter aortic valve implantation. Vessel P/us 2018;2:23. http://dx.doi.org/10.20517/2574-1209.2018.47

Received: 20 Jun 2018 First Decision: 17 Jul 2018 Revised: 15 Aug 2018 Accepted: 17 Aug 2018 Published: 13 Sep 2018

Science Editors: Mario F. L. Gaudino, Cristiano Spadaccio Copy Editor: Yuan-Li Wang Production Editor: Huan-Liang Wu

\begin{abstract}
Transcatheter aortic valve implantation (TAVI) has become in the last years a primary therapeutic tool in order to treat percutaneously severe aortic stenosis in frail patients with multiple comorbidity and a high surgical risk. In almost all cases, the complexity of patients who are candidates for TAVI is also reflected in challenging access sites. This vascular issue addresses the invasive play of constantly evolving devices and resulting complications have a considerable impact on patient morbidity and mortality. For this reason, the study and the choice of the different access site require the attention and experience of the operators to reach the most reliable and feasible vascular approach for a real procedural success.
\end{abstract}

Keywords: Transcatheter aortic valve implantation, vascular access site, access complications

\section{INTRODUCTION}

The transcatheter implantation of the aortic valve is confirmed as a rapidly expanding treatment for severe aortic stenosis in patients with a great risk in terms of mortality to undergo cardiac surgery ${ }^{[1]}$. At the beginning of this experience, a considerable size of sheaths and catheters required a real surgical access for the device insertion, later with the advancement of the technique, the percutaneous approach became more and more common because of its less invasive characteristics ${ }^{[2]}$. However, these procedures are burdened by a significant risk of vascular complications that represent an element of criticality in transcatheter aortic valve implantation (TAVI) performance and are related with adverse events and mortality ${ }^{[3]}$. In fact, these patients are predisposed to high procedural and bleeding risk due to challenging interventions, such as vascular access damage for larger devices but also vessels morbidities and patient frailty ${ }^{[3]}$. The TAVI through femoral

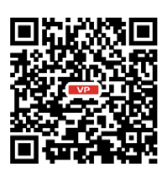


access is recognized as the least invasive and consequently it makes best use of the sheaths currently available. Other access options include transapical access, transaxillary, transcarotid access or a direct aortic approach. These have specific advantages and disadvantages and are used in those cases where there is no fitting anatomy to ensure safer trans-femoral access $(\mathrm{TF})^{[4]}$. In order to achieve procedural success and avoid foreseeable complications, careful planning of the TAVI access site and route is essential. This is achieved through the pre-procedural study of the vessels involved in terms of both caliber and severity of tortuosity and calcification. Therefore, an appropriate high-quality computed tomography (CT) scan with contrast injection is required while arteriography and intravascular ultrasound (IVUS) furnish additional data ${ }^{[5]}$. In this review we describe the different vascular access characteristics as well as the most relevant vascular complications.

\section{TF ACCESS}

Current experts' consensus strongly supports the use of femoral artery as preferred access site for TAVI ${ }^{[6,7]}$. In consideration of the feasibility of using both a surgical and percutaneous approach through the femoral artery, besides the chosen option, the operator's attention must be paid to preserve the vessel from possible damage in its use ${ }^{[6,7]}$. Although, reducing the size of the sheath with the new generation of devices, a small proportion of patients still exhibits unfavourable iliofemoral arteries that compel them to adopt different approaches $^{[4]}$. The techniques of choice for vessel closure, including percutaneous puncture and preliminary suture, are performed under loco-regional anaesthesia and require open surgical access up to $20 \%$ of cases $^{[6,7]}$. These conversions from percutaneous insertions into open or hybrid repairs apply vascular surgery closure techniques or percutaneous closure devices that reproduce them ${ }^{[6,7]}$.

\section{TF access using a surgical cutdown}

Since the sheaths of the first devices show large sizes of about 22-French (Fr) to 24-Fr, early TAVI experiences required surgical access to isolate the artery and access it ${ }^{[7]}$. Surgical approach with tissue cutting and artery exposure is the first step in such a planned procedure and it allows to examine the vessel by checking the quality of the wall identifying optimal puncture site and at the same time potential vascular injuries can easily be controlled and repaired during one procedure. Alternatively, the procedure is performed by percutaneous puncture and the artery is treated surgically only to provide for closure of the vessel ${ }^{[8,9]}$. Reported predictors of vascular complications in TF TAVI include moderate to severe iliofemoral calcified vessels as well as low femoral artery sheath to artery ratio and in this situation performing a surgical approach is preferable ${ }^{[8,9]}$. Moreover, there are cases that deserve particular indications to come along surgically as an excessive depth of the vessel, as in individuals suffering from obesity, the presence of grafts or femoral stents or an anatomy that requires a higher puncture than the standard as in the case of high femoral bifurcation ${ }^{[8,9]}$. However, the surgical approach is associated with wound complications such as lymphoceles, paraesthesia, and potential wound infection which may delay early patient mobilization, a crucial component of the recovery process for elderly patients who are prime candidates for this procedure ${ }^{[10,11]}$. Even if the use of surgery becomes unsustainable due to the the incompetence to accomplish a safe femoral access, it is recommended to consider other possible different accesses in order to avoid predictable complications, arising from the hostility of the route, that inevitably impact on morbidity and mortality of the patient ${ }^{[8,9]}$.

\section{Percutaneous TF Access}

The incidence of major vascular complications have decreased significantly from $15.3 \%$ in the TF cohort of the Placement of AoRTic TraNscathetER Valve Trial (PARTNER) trial utilizing 22 Fr and 24 Fr introducer sheaths to $4.2 \%$ in the Transcatheter Valve Therapy (TVT) Registry. Among them, life-threatening scenario are the thoracic aortic dissection, access-related vascular injury leading to death or significant blood transfusions, distal embolization from a vascular source requiring surgery or resulting in irreversible end-organ damage $^{[12]}$. Thanks to reduced sheath size as well as the improvements in delivery systems and patient selection based on vascular assessment through the CT angiography, TAVI procedure can be done completely 
percutaneously in most of the situations ${ }^{[5]}$. The puncture for this access must be achieved on the common femoral artery tract bounded by the inferior epigastric artery and the femoral bifurcation, this is pivotal for functioning of the potential suture-mediated closure devices. The most recent and widespread sheaths have a size between $14 \mathrm{Fr}$ and $20 \mathrm{Fr}$ and they require femoral arteries of at least $6-6.5 \mathrm{~mm}$ of diameter and deposits of calcium and curves of mild-moderate but not severe degrees. After gaining access, the procedure continues by sliding the device upwards through the entire aorta until the valve plane is reached as previously programmed. Once the position is verified intraoperatively, the deployment of the valve, that is crimped inside the catheter, takes place either by inflating a balloon inside it or by slipping out of the catheter with the self-expanding valve structure ${ }^{[13]}$. To optimize this placement, the ventricle is stimulated at a frequency of 180-200 bpm to lower the cardiac motion. After positioning the valve, the device is carefully pulled out, the anticoagulant is reversed and the entry breach is closed. In patients with severe atherosclerotic disease characterized by multiple critical stenoses, large calcium plaques and forbidding angles, the use of femoral access is unnecessarily risky and harmful, and we can affirm the same for aneurysmal pathology. In these cases, it is important to study solutions using other possible ways to accomplish the TAVI ${ }^{[8]}$. The advantages of achieving the implantation in a totally percutaneous way include the use of local anaesthesia with the awake and collaborating patient as well as a rapid mobilization of the patient and a reduction in hospitalization time ${ }^{[14,15]}$. Closing tools and techniques seem to have favourable outcomes and have been increasingly used; however due to the large caliber of the sheaths, vigilant closure is necessary to be effective ${ }^{[14,15]}$. After removing the sheath, the suture threads with the guidance of additional devices such as ProGlide or ProStar as a "pre-closure" technique are definitely bound. In details, with the ProGlide system the femoral artery is punctured and dilated with a standard arterial sheath. Then, the ProGlide device is advanced over the guidewire, and the first suture is deployed slightly angulated at the 10 o'clock position. Guidewire access is maintained, and a second ProGlide device is inserted and deployed at the 2 o'clock position ${ }^{[16]}$. Instead, the ProStar device is advanced over the guidewire until the dedicated marker lumen shows blood marking, indicating that the sutures and needles are within the vessel lumen. The needles are pulled back while maintaining the position and entry angle of the ProStar device. The device is retracted, and the guidewire is reinserted through its gate. Then the device is removed, and a dilator is inserted ${ }^{[17]}$. At this point, similarly for both the systems, a regular J wire can be exchanged for a stiffer wire, and the large sheath is advanced under fluoroscopy. After conclusion of the procedure the introducer sheath is removed, the guidewire is left in position and then slowly withdrawn until haemostasis is achieved since it represents the possibility to access to the artery in the event of bleeding due to the lack of effectiveness of the closure ${ }^{[16,17]}$. If successful, the suture knot is well tight and consolidated. Both the ProStar and ProGlide devices require experience and a check angiography is usually performed by contralateral access and it verifies the absence of injuries in the iliac and femoral vascular structures. The closure of all percutaneous endovascular access is related to a lower incidence of late groin complications and a diminished procedural time $\mathrm{e}^{[14,15]}$.

\section{Percutaneous vs, surgical cut-down in TF TAVI}

Earlier studies concerning percutaneous endovascular repair of aortic aneurysm indicated comparable feasibility and safety of the complete percutaneous femoral approach compared to surgical cut-down and repair $^{[18]}$. More recently, several studies have reported complete percutaneous access and closure using the cross-over technique on the access for device deployment in TF TAVI. They suggest comparable expediency and security of this novel technique as a potential alternative to the surgical approach on arterial access of TF TAVI ${ }^{[19]}$. Compared to the surgical approach, the complete percutaneous approach using pre-closure technique for arterial access/closure of large caliber sheaths (22 Fr or $24 \mathrm{Fr}$ ) for TAVI is suitable with acceptable safety and potential clinical benefit including reduction in wound infection, lowering bleeding complication, and reduced hospital stay while maintaining similar major vascular event rate ${ }^{[19]}$. Nevertheless, the incidence of access site vascular events is still higher in the complete percutaneous group even though this did not appear to affect in-hospital mortality or length of hospital stay if it is recognized in timely manner and appropriately managed ${ }^{[19,20]}$. 


\section{TRANSAPICAL ACCESS}

The transapical access must be performed under general anaesthesia and preferably in a hybrid operating room in order to have the surgical and transcatheter equipment ready for use and to the best of the possibilities $^{[21]}$. Briefly, a small left anterior mini-thoracotomy is performed in the fifth-sixth intercostal space to expose the apex of the left ventricle after opening the pericardium. In order to visualize and fix the operating window, the pericardium is anchored with several points to the skin. Polypropylene sutures forming a purse concentrically, usually in the number of two, are positioned catching wide portions of cardiac apex tissue. So, via the above-mentioned threads, the operator introduces the sheath into the left ventricle ${ }^{[22]}$. After transcatheter placement of the valve, the sheath is retracted and the sutures are tightened during rapid ventricular pacing to maintain low pressure in the final repair time. Transapical access approach is a "surgical" procedure without impairing of the thoracic cage and has the theoretical advantages of stroke prevention avoiding to cross the aortic arch with the device during the delivery ${ }^{[21,22]}$. Contrary to the direct aortic approach, transapical approach can be used only with the SAPIEN valve that can be assembled backwards ${ }^{[23]}$. This access is advantageous especially in patients in whom the pre-procedure evaluation shows characteristics that determine a high risk of stroke and embolism as in the case of extensive calcifications, porcelain aorta and thrombus finding in the aortic $\operatorname{arch}^{[22]}$.

\section{DIRECT AORTIC ACCESS}

Direct transaortic access is one of the possibilities of a transcatheter implantation using a surgical access and it is either performed by a J-shaped mini-sternotomy or a right thoracotomy. The purpose of the operating window is to visualize an initial portion of the ascending aorta for the introduction of the valve delivery device. Depending on the anatomical position of the aorta, one of the two windows is suggested. The right thoracotomy is recommended in cases where the aorta runs in the right hemithorax and superficially near the rib cage, while the mini-sternotomy is chosen in those cases in which the vessel is in a central and deep position $^{[24]}$. Once the window is realized, a suture bag is obtained on the designated aorta section for the final closure and, in the center of the managed area, the access to the vessel is first performed with a needle puncture and then with the device. The insertion of the device into the aorta must take into account the type of valve that is implanted, for example for Medtronic CoreValve a distance of at least 6-7 cm from the valve plane is necessary in order to ensure the complete deployment of the skeleton from the sheath. Using this wire as a rail, the device slides up to the aortic valve. In this approach, the position of the valve prosthesis is promoted by the shortness of the path between the access and the valve and by the absence of stress on the device as it happens in the femoral access for the passage in the aortic arch. Favourably, these conditions allow a short learning curve by the operator ${ }^{[25,26]}$.

After the valve implantation, the device is withdrawn while the previously prepared suture threads are tightened to close the vessel wall, the technique is comparable to decannulation after cardiopulmonary bypass. Finally, the chest wall is restored as usually occurs in cardio-thoracic surgery. The hemisternotomy allows to protect the pleura and to visualize and handle a large portion of aorta in which to select the access point. In case of patients with coronary bypass graft, it is advisable to use the thoracotomy to avoid its course ${ }^{[25,26]}$. Finally, the direct aortic approach is suitable if the patient has a horizontal valvular plane or a particularly straight ascending aorta ${ }^{[25,26]}$.

\section{TRANSUBCLAVIAN}

The approach through the subclavian artery takes advantage of a light sedation and local anaesthetic. In order to adequately display the artery, an incision is made between the deltopectoral groove and the pectoralis major. This technique is less invasive than a real surgical support and, at the same time, it overcomes a possible impairment of the peripheral accesses ${ }^{[27]}$. The brachial plexus, one of the most important nerve bundles of our body, is located above the subclavian artery and for this reason it is fundamental to protect it from 
complications such as artery dissection or pseudoaneurysm ${ }^{[28]}$. The artery can be highlighted by a band if it is accomplished through a surgical isolation and, as seen in other accesses, a suture purse is created with a 5-0 polypropylene thread on the front side of the vessel, both for safety and for the final closure. Considering a vessel without calcific disease, a minimum of $6 \mathrm{~mm}$ is required for the introduction of a $18 \mathrm{Fr}$ sheath while in the case of the presence of a patent's left internal mammary artery graft, the diameter must be at least $7.5 \mathrm{~mm}$ to maintain a sustainable downstream flow ${ }^{[27,28]}$. The artery is pierced with a standard needle which is inserted in the center of the prepared sutured area, on that insertion point a soft 0.035 wire with a J-tip is introduced and a 6 Fr sheath is inserted on it. A catheter slides over the wire in the ascending aorta, then the soft wire is replaced with a super-stiff Amplatz wire. So, in order to get the $18 \mathrm{Fr}$ sheath through the subclavian artery in the proximal ascending aorta, a series of increasing size of dilators, from $10 \mathrm{Fr}, 12 \mathrm{Fr}$, $14 \mathrm{Fr}$ up to $18 \mathrm{Fr}$, follow each other at the insertion point ${ }^{[27,28]}$. The succeeding steps for the valve deployment adhere to the standard protocol of the procedure. After the sheath is removed, the purse-string suture is tied under direct visualization that would determine if additional sutures are needed. Continuous advances of this technique have recently leaded to publications of fully percutaneous procedures without surgical cutdown ${ }^{[27,28]}$. However, these improvements are not yet able to displace surgical exposure as the routine practice $^{[29]}$. Performing a transubclavian approach may be particularly challenging if the aortic plane forms an angle greater than 30 degrees with the horizontal plane. This complexity derives from the curving that the device must perform and from the consequent tension on it, increasing the difficulty in the proper deployment of the prosthesis ${ }^{[28,29]}$.

Furthermore, the occlusion of the vessel by the sheath or any damage to neighbouring vascular structures may result in dangerous ischemia, especially when it involves the flow of an internal mammary artery graft with possible myocardial infarction in the most severe conditions ${ }^{[28,29]}$.

\section{TRANSCAROTID}

Among the possible strategies, an approach with a direct and short road to reach the planned position at the aortic valve plane is always recommended. This can also be achieved with the carotid access as well as with the transaortic and transapical approach ${ }^{[30]}$. A short path also allows a better support and greater precision in valve distribution than the femoral approach ${ }^{[30]}$. The patient is evaluated preliminarily to define the possibility of performing the procedure with the necessary occlusion of one carotid and therefore the maintenance of an adequate cerebral flow through the Willis circle from the contralateral carotid ${ }^{[31]}$. This is assessed by placing a shunt in the vessel to measure passive anterograde pressure in the common carotid artery, then the procedure is performed using a small cut as access under local anaesthesia ${ }^{[31]}$. The first series with this approach, through the proximal left common carotid artery, is reported by Modine et al. ${ }^{[32]}$ and it counts 12 consecutive cases performed under general anaesthesia. The study does not report peri-procedural events, vascular complications or bleedings, the only adverse event recorded is an embolic transient ischemic attack starting from the contralateral carotid access ${ }^{[32]}$. Later, a study publishes a series of cases under local anaesthesia using both balloon expandable and self-expandable valve. Even if the study does not report access site complications, major adverse cardiac event or stroke, two patients died, one during valvuloplasty and one for multiple organ failure. Finally, three patients developed a third-degree atrioventricular block resulting in a definitive pacemaker implantation ${ }^{[30]}$. Therefore, we can conclude that this type of approach requires further studies and technical evolutions in order to be able to enter currently as an access option, considering also the possible aesthetic issue that could derive from it.

\section{TRANSCAVAL}

Another recently developed approach is the transcaval-aortic access which can be a useful alternative in cases of severe peripheral artery disease. The access puncture is performed at the femoral vein site, reaching the abdominal aorta and creating an artificial cava-aorta fistula. The characteristics of the venous wall allow 
an easy insertion of the oversized TAVI sheath. Furthermore, retroperitoneal anatomical structures guarantee a low risk of bleeding that may be due primarily to the arterio-venous shunt, which is repaired with an occluder device at the end of the procedure ${ }^{[33]}$.

The main challenge of this approach is the making of the cava-aorta connection through the intersection of the two vessel walls at the abdominal level. This can require multiple attempts by less experienced operators to achieve the entry in aorta, the use of haemostatic techniques, transfusions and the treating of leaks due to ineffective repairs. However, the learning curve appears to be short and procedural times are similar to those of femoral access ${ }^{[34]}$.

Considering the importance of the vascular roadmap to reach the aortic annulus for the valve implantation, the evaluation of the pre-procedure CT study becomes fundamental for the assessment of the calcifications, the diameters and the tortuosity of the vessels. Specifically, the crossing of the cava-aorta requires careful evaluation of the calcification and of secondary branches in order to allow a successful closure of the iatrogenic fistula with an occluder device. Porcelain aorta, previous abdominal endograft and other abnormalities of the aortic wall, represent a contraindication to this access, like an iliac severe tortuosity for the femoral access $^{[35]}$.

So, this approach is a valid option only in patients with a precise vascular anatomy and the for its hidden tricks it should be performed by skilled operators in experienced centers. Finally, it needs further studies, especially about the safety of the method ${ }^{[36]}$.

\section{COMPARISON AMONG ACCESS SITE}

The safety and performance of the TF approach, that have been achieved thanks to the extensive TAVI experience, are the main model of comparison for other access options. The TF approach is to be considered the only completely percutaneous access with the use of the femoral crossover technique and vascular closure devices. Alternative routes are subject to the inability to perform the procedure through the femoral access and they are identified as independent predictors of overall and cardiovascular mortality at 5 years in the real-world population ${ }^{[37]}$.

TA and transubclavian access are the most used routes in presence of contraindications to the femoral approach and they both show high rates of procedural success. The only difference between them and the TF, although it is not statistically significant, is represented by a greater incidence of potentially fatal bleeding for the trans-apical approach ${ }^{[38]}$.

Studies reveal a reduction in vascular complication rate using transapical and trans-subclavian access compared to a fully percutaneous femoral access. While this is easily understood for the transapical access due to its inherent features, data for the trans-subclavian are difficult to explain ${ }^{[39]}$.

A comparison between TF versus transubclavian access produces no considerable differences in 30 days mortality, stroke and new pacemaker implantation. Similarly to the transubclavian access, the trans-axillary compared to the TF approach shows no relevant differences in 30 days mortality but it needs general anaesthesia more frequently and leads to a greater tendency of vascular complications ${ }^{[40]}$.

On the other hand, the trans-apical approach is a more invasive procedure and involves a higher rate of surgical conversion, longer hospitalization, a higher rate of renal failure and higher mortality rates than the TF route $^{[41]}$. Furthermore, no statistically significant differences are reported in stroke incidence and new pacemaker implantation using the trans-apical compare to the femoral access ${ }^{[39-41]}$. 


\section{VASCULAR ACCESS SITE COMPLICATIONS}

The most used access for TAVI is the femoral one, which represents $70 \%$ of the procedures ${ }^{[42]}$.

The most common complications performing TAVI are the dissection and rupture of the vessels that represent the vascular route of the valve device, so the vessels of the hip, pelvis, the aorta at the abdominal level and the aortic arch. Moreover, complications on the puncture site such as hematoma and pseudoaneurysm are recurrent ${ }^{[42]}$. The importance of complications derives from their proven impact on mortality and hospitalization which disposes to further complications ${ }^{[43,44]}$. From the standardization of the Valve Academic Research Consortium (VARC) definitions, the assessment of complications frequency is more accurate. The incidence of major vascular complications is ranged between $10 \%$ and $20 \%$ while minor vascular complications are around $10.2 \%{ }^{[44]}$.

Since the valve is squeezed into the catheter for the deployment, the greater the diameter of the valve, the greater will be the diameter of the catheter and, therefore, the greater the complications for the trauma of the passage of the device inside vessels ${ }^{[45]}$. In particular, a ratio between the diameter of the sheath and that of the femoral artery above 1.05 is considered risky, as well as unskilled operator, center with limited experience, severe calcifications and a sheath size greater than $19 \mathrm{Fr}^{[44-46]}$.

In fact, in a large European multicentric registry, the prevalent use of the 18 Fr device brings to a considerable decrease of vascular complications, with a $2.9 \%$ for the trans-femoral access ${ }^{[47]}$. The study shows no difference in vascular complications between the two main devices Medtronic Core Valve versus Edwards SAPIEN XT valves with a rate of $2.8 \%$ and $3.3 \%$ respectively $(P=0.66)^{[47]}$. We are dealing with a further reduction of complications with the introduction of the new 14 Fr systems.

\section{ACCESS AND BLEEDING}

The formation of hematomas and the presence of bleeding at the TAVI access site are common complications, estimated between $11 \%$ and $18 \%$ of patients ${ }^{[48]}$. As previously stated, complications and therefore also haemorrhage and hematoma of the access site result in longer hospitalization for their management or for the treatment of further complications such as infections ${ }^{[47-49]}$.

Following the reduction of the diameter of the devices and the improvement of the technique and experience of the operators and centers, there was a decrease in bleeding rates. A prompt management of bleedings and hematomas is essential, the less severe cases can be solved with adequate compression, possibly under ultrasound guidance. Hematomas of larger size, due to diagnosed late or creating compression of the surrounding tissue, must be treated surgically ${ }^{[50]}$. Finally, in case of adequately early diagnosis and after failure of a compressive first treatment, endovascular techniques are used through a contralateral femoral access. These consist in prolonged inflation of a balloon at the level of the hole of vessel wall and in case of failure of this approach, angioplasty is performed with the placement of a covered stent ${ }^{[51]}$.

\section{CONCLUSION}

The indications for TAVI are expanding and the always more skilled operators must guarantee the best approach in terms of safety and procedural success. On the other hand, the devices make important progress on technical aspects, becoming smaller, with easy delivery, accurate positioning and thus realizing the valve implantation in a more feasible and effective way.

Access site is one of the main topic to assure the TAVI safety and in order to choose the best approach for every patient and plan successful strategy of implantation, the preprocedural CT angiography study results are fundamental. Especially in patients with difficult access, the evaluation of risk factors and the experience 
in endovascular techniques allow the operators to predict, face promptly and overcome vascular access complications.

Whatever the access and the chosen strategy, a discerning management of the access site in structural procedures, such as TAVI, allows to protect the patient from a high morbidity and mortality.

\section{DECLARATIONS}

\section{Authors' contributions}

Planning and writing: Sticchi A

Writing: Bressi E

Revision of the manuscript: Nusca A, Di Sciascio G

\section{Availability of data and materials}

Not applicable.

\section{Financial support and sponsorship}

None.

\section{Conflicts of interest}

All authors declared that there are no conflicts of interest.

\section{Ethical approval and consent to participate}

Not applicable.

\section{Consent for publication}

Not applicable.

\section{Copyright}

(c) The Author(s) 2018.

\section{REFERENCES}

1. Baumgartner H, Falk V, Bax JJ, De Bonis M, Hamm C, Holm PJ, Iung B, Lancellotti P, Lansac E, Rodriguez Muñoz D, Rosenhek R, Sjögren J, Tornos Mas P, Vahanian A, Walther T, Wendler O, Windecker S, Zamorano JL; ESC Scientific Document Group. 2017 ESC/ EACTS Guidelines for the management of valvular heart disease. Eur Heart J. 2017;38:2739-91.

2. Reardon MJ, Van Mieghem NM, Popma JJ, Kleiman NS, Søndergaard L, Mumtaz M, Adams DH, Deeb GM, Maini B, Gada H, Chetcuti S, Gleason T, Heiser J, Lange R, Merhi W, Oh JK, Olsen PS, Piazza N, Williams M, Windecker S, Yakubov SJ, Grube E, Makkar R, Lee JS, Conte J, Vang E, Nguyen H, Chang Y, Mugglin AS, Serruys PW, Kappetein AP; SURTAVI Investigators. Surgical or transcatheter aortic-valve replacement in intermediate-risk patients. N Engl J Med 2017;376:1321-31.

3. Zajarias A, Cribier AG. Outcomes and safety of percutaneous aortic valve replacement. J Am Coll Cardiol 2009;53:1829-36.

4. Holmes DR, Jr, Mack MJ. Transcatheter valve therapy: a professional society overview from the American College of Cardiology Foundation and the Society of Thoracic Surgeons. Ann Thorac Surg 2011;92:380-9.

5. Willson AB, Webb JG, Labounty TM, Achenbach S, Moss R, Wheeler M, Thompson C, Min JK, Gurvitch R, Norgaard BL, Hague CJ, Toggweiler S, Binder R, Freeman M, Poulter R, Poulsen S, Wood DA, Leipsic J. 3-dimensional aortic annular assessment by multidetector computed tomography predicts moderate or severe paravalvular regurgitation after transcatheter aortic valve replacement: a multicenter retrospective analysis. J Am Coll Cardiol 2012;59:1287-94.

6. Gilard M1, Eltchaninoff H, Iung B, Donzeau-Gouge P, Chevreul K, Fajadet J, Leprince P, Leguerrier A, Lievre M, Prat A, Teiger E, Lefevre T, Himbert D, Tchetche D, Carrié D, Albat B, Cribier A, Rioufol G, Sudre A, Blanchard D, Collet F, Dos Santos P, Meneveau N, Tirouvanziam A, Caussin C, Guyon P, Boschat J, Le Breton H, Collart F, Houel R, Delpine S, Souteyrand G, Favereau X, Ohlmann P, Doisy V, Grollier G, Gommeaux A, Claudel JP, Bourlon F, Bertrand B, Van Belle E, Laskar M; FRANCE 2 Investigators. Registry of transcatheter aortic-valve implantation in high-risk patients. N Engl J Med 2012;366:1705-15.

7. Webb JG, Altwegg L, Boone RH, Cheung A, Ye J, Lichtenstein S, Lee M, Masson JB, Thompson C, Moss R, Carere R, Munt B, 
Nietlispach F, Humphries K. Transcatheter aortic valve implantation: impact on clinical and valve-related outcomes. Circulation 2009;119:3009-16.

8. Toggweiler S, Webb JG. Challenges in transcatheter aortic valve implantation. Swiss Med Wkly 2012;142:w13735.

9. Thomas M, Schymik G, Walther T, Himbert D, Lefèvre T, Treede H, Eggebrecht H, Rubino P, Colombo A, Lange R, Schwarz RR, Wendler O. One-year outcomes of cohort 1 in the Edwards SAPIEN Aortic Bioprosthesis European Outcome (SOURCE) registry: the European registry of transcatheter aortic valve implantation using the Edwards SAPIEN valve. Circulation 2011;124:425-33.

10. Tirado-Conte G, Freitas-Ferraz AB, Nombela-Franco L, Jimenez-Quevedo P, Biagioni C, Cuadrado A, Nuñez-Gil I, Salinas P, Gonzalo N, Ferrera C, Vivas D, Higueras J, Viana-Tejedor A, Perez-Vizcayno MJ, Vilacosta I, Escaned J, Fernandez-Ortiz A, Macaya C. Incidence, causes, and impact of in-hospital infections after transcatheter aortic valve implantation. Am J Cardiol 2016;118:403-9.

11. Al-Rashid F, Kahlert P, Selge F, Hildebrandt H, Patsalis PC, Totzeck M, Mummel P, Rassaf T, Jánosi RA. Risk assessment of patients undergoing transfemoral aortic valve implantation upon admission for post-interventional intensive care and surveillance: implications on short- and midterm outcomes. PLoS One 2016;11:e0167072.

12. Leon MB, Smith CR, Mack MJ, Makkar RR, Svensson LG, Kodali SK, Thourani VH, Tuzcu EM, Miller DC, Herrmann HC, Doshi D, Cohen DJ, Pichard AD, Kapadia S, Dewey T, Babaliaros V, Szeto WY, Williams MR, Kereiakes D, Zajarias A, Greason KL, Whisenant BK, Hodson RW, Moses JW, Trento A, Brown DL, Fearon WF, Pibarot P, Hahn RT, Jaber WA, Anderson WN, Alu MC, Webb JG; PARTNER 2 Investigators. Transcatheter or surgical aortic-valve replacement in intermediate-risk patients. N Engl J Med 2016;374:1609-20.

13. van der Boon RM, Van Mieghem NM, Theuns DA, Nuis RJ, Nauta ST, Serruys PW, Jordaens L, van Domburg RT, de Jaegere PP. Pacemaker dependency after transcatheter aortic valve implantation with the self-expanding Medtronic CoreValve System. Int J Cardiol 2013;168:1269-73.

14. Hayashida K, Lefèvre T, Chevalier B, Hovasse T, Romano M, Garot P, Mylotte D, Uribe J, Farge A, Donzeau-Gouge P, Bouvier E, Cormier B, Morice MC. True percutaneous approach for transfemoral aortic valve implantation using the Prostar XL device: impact of learning curve on vascular complications. JACC Cardiovasc Interv 2012;5:207-14.

15. Sharp AS, Michev I, Maisano F, Taramasso M, Godino C, Latib A, Denti P, Dorigo E, Giacomini A, Iaci G, Manca M, Ielasi A, Montorfano M, Alfieri O, Colombo A. A new technique for vascular access management in transcatheter aortic valve implantation. Catheter Cardiovasc Interv 2010;75:784-93.

16. Dimitriadis Z, Scholtz W, Ensminger SM, Piper C, Bitter T, Wiemer M, Vlachojannis M, Börgermann J, Faber L, Horstkotte D, Gummert J, Scholtz S. Impact of sheath diameter of different sheath types on vascular complications and mortality in transfemoral TAVI approaches using the ProGlide closure device. PLoS One 2017;12:e0183658.

17. Hayashida K, Lefèvre T, Chevalier B, Hovasse T, Romano M, Garot P, Mylotte D, Uribe J, Farge A, Donzeau-Gouge P, Bouvier E, Cormier B, Morice MC. True percutaneous approach for transfemoral aortic valve implantation using the Prostar XL device: impact of learning curve on vascular complications. JACC Cardiovasc Interv 2012;5:207-14.

18. Jean-Baptiste E, Hassen-Khodja R, Haudebourg P, Bouillanne PJ, Declemy S, Batt M. Percutaneous closure devices for endovascular repair of infrarenal abdominal aortic aneurysms: a prospective, non-randomized comparative study. Eur J Vasc Endovasc Surg 2008; 35: $422-8$.

19. Sharp AS, Michev I, Maisano F, Taramasso M, Godino C, Latib A, Denti P, Dorigo E, Giacomini A, Iaci G, Manca M, Ielasi A, Montorfano M, Alfieri O, Colombo A. A new technique for vascular access management in transcatheter aortic valve implantation. Catheter Cardiovasc Interv 2010;75:784-93.

20. Nakamura M1, Chakravarty T, Jilaihawi H, Doctor N, Dohad S, Fontana G, Cheng W, Makkar RR. Complete percutaneous approach for arterial access in transfemoral transcatheter aortic valve replacement: a comparison with surgical cut-down and closure. Catheter Cardiovasc Interv 2014;84:293-300.

21. Lichtenstein SV, Cheung A, Ye J, Thompson CR, Carere RG, Pasupati S, Webb JG. Transapical transcatheter aortic valve implantation in humans: initial clinical experience. Circulation 2006;114:591-6.

22. Walther T, Möllmann H, van Linden A, Kempfert J. Transcatheter aortic valve implantation transapical: step by step. Semin Thorac Cardiovasc Surg 2011;23:55-61.

23. Walther T, Kempfert J, Dewey T. Transapical aortic valve implantation - procedural steps. In: Serruys PW Piazza N, Cribier A, Webb JG, Laborde JC, de Jaegere P, editors. Transcatheter aortic valve implantation. Tips and tricks to avoid failure. New York: Informa Healthcare USA, Inc.; 2010. p. 207-17.

24. Bruschi G, De Marco F, Fratto P, Oreglia J, Colombo P, Paino R, Klugmann S, Martinelli L. Direct aortic access through right minithoracotomy for implantation of self-expanding aortic bioprosthetic valves. J Thorac Cardiovasc Surg 2010;140:715-7.

25. Bapat VN, Bruschi G. Transaortic access is the key to success. EuroIntervention 2013;9 Suppl:S25-32.

26. Lardizabal JA, O'Neill BP, Desai HV, Macon CJ, Rodriguez AP, Martinez CA, Alfonso CE, Bilsker MS, Carillo RG, Cohen MG, Heldman AW, O'Neill WW, Williams DB. The transaortic approach for transcatheter aortic valve replacement: initial clinical experience in the United States. J Am Coll Cardiol 2013;61:2341-5.

27. Caceres M, Braud R, Roselli EE. The axillary/subclavian artery access route for transcatheter aortic valve replacement: a systematic review of the literature. Ann Thorac Surg 2012;93:1013-8.

28. van Mieghem NM, Lüthen C, Oei F, Schultz C, Ligthart J, Kappetein AP, de Jaegere PP. Completely percutaneous transcatheter aortic valve implantation through transaxillary route: an evolving concept. EuroIntervention 2012;7:1340-2.

29. Schäfer U, Ho Y, Frerker C, Schewel D, Sanchez-Quintana D, Schofer J, Bijuklic K, Meincke F, Thielsen T, Kreidel F, Kuck KH. Direct percutaneous access technique for transaxillary transcatheter aortic valve implantation: "the Hamburg Sankt Georg approach". JACC 
Cardiovasc Interv 2012;5:477-86.

30. Azmoun A, Amabile N, Ramadan R, Ghostine S, Caussin C, Fradi S, Raoux F, Brenot P, Nottin R, Deleuze P. Transcatheter aortic valve implantation through carotid artery access under local anaesthesia. Eur J Cardiothorac Surg 2014;46:693-8.

31. Guyton RA, Block PC, Thourani VH, Lerakis S, Babaliaros V. Carotid artery access for transcatheter aortic valve replacement. Catheter Cardiovasc Interv 2013;82:E583-6.

32. Modine T, Sudre A, Delhaye C, Fayad G, Lemesle G, Collet F, Koussa M. Transcutaneous aortic valve implantation using the left carotid access: feasibility and early clinical outcomes. Ann Thorac Surg 2012;93:1489-94.

33. Halabi M, Ratnayaka K, Faranesh AZ, Chen MY, Schenke WH, Lederman RJ. Aortic access from the vena cava for large caliber transcatheter cardiovascular interventions: pre-clinical validation. J Am Coll Cardiol 2013;61:1745-6.

34. Greenbaum AB, O'Neill WW, Paone G, Guerrero ME, Wyman JF, Cooper RL, Lederman RJ. Caval-aortic access to allow transcatheter aortic valve replacement in otherwise ineligible patients: initial human experience. J Am Coll Cardiol 2014;63:2795-804.

35. Pascual I, Carro A, Avanzas P, Hernández-Vaquero D, Díaz R, Rozado J, Lorca R, Martín M, Silva J, Morís C. Vascular approaches for transcatheter aortic valve implantation. J Thorac Dis 2017;9:S478-87.

36. Lederman RJ, Babaliaros VC, Greenbaum AB. How to perform transcaval access and closure for transcatheter aortic valve implantation. Catheter Cardiovasc Interv 2015;86:1242-54.

37. Ruparelia N, Latib A, Buzzatti N, Giannini F, Figini F, Mangieri A, Regazzoli D, Stella S, Sticchi A, Kawamoto H, Tanaka A, Agricola E, Monaco F, Castiglioni A, Ancona M, Cioni M, Spagnolo P, Chieffo A, Montorfano M, Alfieri O, Colombo A. Long-term outcomes after transcatheter aortic valve implantation from a single high-volume center (The Milan Experience). Am J Cardiol 2016;117:813-9.

38. Ciuca C, Tarantini G, Latib A, Gasparetto V, Savini C, Di Eusanio M, Napodano M, Maisano F, Gerosa G, Sticchi A, Marzocchi A, Alfieri O, Colombo A, Saia F. Trans-subclavian versus transapical access for transcatheter aortic valve implantation: a multicenter study. Catheter Cardiovasc Interv 2016;87:332-8.

39. Garcia DC, Benjo A, Cardoso RN, Macedo FY, Chavez P, Aziz EF, Herzog E, Alam M, de Marchena E. Device stratified comparison among transfemoral, transapical and transubclavian access for transcatheter aortic valve replacement (TAVR): a meta-analysis. Int J Cardiol 2014;172:e318-21.

40. Chandrasekhar J, Hibbert B, Ruel M, Lam BK, Labinaz M, Glover C. Transfemoral vs non-transfemoral access for transcatheter aortic valve implantation: a systematic review and meta-analysis. Can J Cardiol 2015;31:1427-38.

41. Shults C, Gunter R, Thourani VH. The versatility of transapical access: will it lead to a completely new approach to valvular therapy? Ann Cardiothorac Surg 2012;1:220-3.

42. Stortecky S, Buellesfeld L, Wenaweser P, Windecker S. Transcatheter aortic valve implantation: the procedure. Heart 2012;98:iv44-51.

43. Généreux P, Webb JG, Svensson LG, Kodali SK, Satler LF, Fearon WF, Davidson CJ, Eisenhauer AC, Makkar RR, Bergman GW, Babaliaros V, Bavaria JE, Velazquez OC, Williams MR, Hueter I, Xu K, Leon MB; PARTNER Trial Investigators. Vascular complications after transcatheter aortic valve replacement: insights from the PARTNER (Placement of AoRTic TraNscathetER Valve) trial. J Am Coll Cardiol 2012;60:1043-52.

44. Hayashida K, Lefèvre T, Chevalier B, Hovasse T, Romano M, Garot P, Mylotte D, Uribe J, Farge A, Donzeau-Gouge P, Bouvier E, Cormier B, Morice MC. Transfemoral aortic valve implantation new criteria to predict vascular complications. JACC Cardiovasc Interv 2011;4:851-8.

45. Reidy C, Sophocles A, Ramakrishna H, Ghadimi K, Patel PA, Augoustides JG. Challenges after the first decade of transcatheter aortic valve replacement: focus on vascular complications, stroke, and paravalvular leak. J Cardiothorac Vasc Anesth 2013;27:184-9.

46. Toggweiler S, Gurvitch R, Leipsic J, Wood DA, Willson AB, Binder RK, Cheung A, Ye J, Webb JG. Percutaneous aortic valve replacement: vascular outcomes with a fully percutaneous procedure. J Am Coll Cardiol 2012;59:113-8.

47. Di Mario C, Eltchaninoff H, Moat N, Goicolea J, Ussia GP, Kala P, Wenaweser P, Zembala M, Nickenig G, Alegria Barrero E, Snow T, Iung B, Zamorano P, Schuler G, Corti R, Alfieri O, Prendergast B, Ludman P, Windecker S, Sabate M, Gilard M, Witowski A, Danenberg H, Schroeder E, Romeo F, Macaya C, Derumeaux G, Maggioni A, Tavazzi L; Transcatheter Valve Treatment Sentinel Registry (TCVT) Investigators of the EURObservational Research Programme (EORP) of the European Society of Cardiology. The 2011-12 pilot European Sentinel Registry of Transcatheter Aortic Valve Implantation: in-hospital results in 4,571 patients. EuroIntervention 2013;8:1362-71.

48. Van Mieghem NM, Tchetche D, Chieffo A, Dumonteil N, Messika-Zeitoun D, van der Boon RM, Vahdat O, Buchanan GL, Marcheix B, Himbert D, Serruys PW, Fajadet J, Colombo A, Carrié D, Vahanian A, de Jaegere PP. Incidence, predictors, and implications of access site complications with transfemoral transcatheter aortic valve implantation. Am J Cardiol 2012;110:1361-7.

49. Mussardo M, Latib A, Chieffo A, Godino C, Ielasi A, Cioni M, Takagi K, Davidavicius G, Montorfano M, Maisano F, Carlino M, Franco A, Covello RD, Spagnolo P, Grimaldi A, Alfieri O, Colombo A. Periprocedural and short-term outcomes of transfemoral transcatheter aortic valve implantation with the Sapien XT as compared with the Edwards Sapien valve. JACC Cardiovasc Interv 2011;4:743-50.

50. De Backer O, Arnous S, Sandholt B, Brooks M, Biasco L, Franzen O, Lönn L, Bech B, Søndergaard L. Safety and efficacy of using the Viabahn endoprosthesis for percutaneous treatment of vascular access complications after transfemoral aortic valve implantation. Am J Cardiol 2015;115:1123-9.

51. Starnes BW, Arthurs ZM. Endovascular management of vascular trauma. Perspect Vasc Surg Endovasc Ther 2006;18:114-29. 